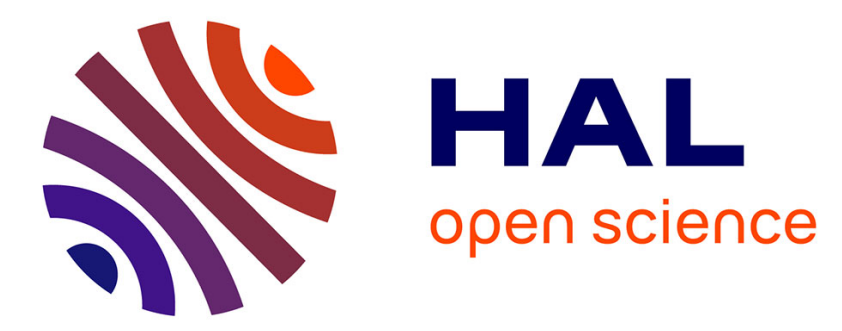

\title{
Synthesis, Characterization, and Solid-State Properties of (CH2-CH2-C(COOH)2)n : A Highly Symmetrical, Semicrystalline Carbon-Chain Poly(carboxylic acid)
}

\author{
Antoine Benlahouès, Blandine Brissault, Agustin Rios de Anda, Jacques \\ Penelle
}

\section{To cite this version:}

Antoine Benlahouès, Blandine Brissault, Agustin Rios de Anda, Jacques Penelle. Synthesis, Characterization, and Solid-State Properties of $(\mathrm{CH} 2-\mathrm{CH} 2-\mathrm{C}(\mathrm{COOH}) 2) n$ : A Highly Symmetrical, Semicrystalline Carbon-Chain Poly(carboxylic acid). Macromolecules, 2020, 53 (15), pp.6204-6212. 10.1021/acs.macromol.9b02665 . hal-02971522

\author{
HAL Id: hal-02971522 \\ https://hal.science/hal-02971522
}

Submitted on 7 Dec 2020

HAL is a multi-disciplinary open access archive for the deposit and dissemination of scientific research documents, whether they are published or not. The documents may come from teaching and research institutions in France or abroad, or from public or private research centers.
L'archive ouverte pluridisciplinaire HAL, est destinée au dépôt et à la diffusion de documents scientifiques de niveau recherche, publiés ou non, émanant des établissements d'enseignement et de recherche français ou étrangers, des laboratoires publics ou privés. 


\section{Synthesis, Characterization and Solid-State}

\section{Properties of $\left(\mathrm{CH}_{2}-\mathrm{CH}_{2}-\mathrm{C}(\mathrm{COOH})_{2}\right)_{n}$, a Highly}

\section{Symmetrical, Semi-Crystalline Carbon-Chain}

\section{Polycarboxylic Acid}

Antoine Benlahouès, Blandine Brissault, Agustin Rios de Anda* and Jacques Penelle*

Institut de Chimie et des Matériaux Paris-Est (East Paris Institute for Chemistry \& Materials

Science), Université Paris-Est and CNRS, 2-8 rue H. Dunant, F-94320 Thiais, France

KEYWORDS: Polyacids, Semicrystalline polymers, Wetting, Structure-property relationships in the solid-state, Self-associating polymers, Hydrogen bonding, FT-IR, WAXS, Solid-State NMR

ABSTRACT: The synthesis and structural characterization of poly(trimethylene-1,1dicarboxylic acid), $\left(\mathrm{CH}_{2}-\mathrm{CH}_{2}-\mathrm{C}(\mathrm{COOH})_{2}\right)_{\mathrm{n}}$, a carbon-chain polymer bearing two carboxylic acids on every third carbon alongside the backbone is described for the first time. Solid-state properties are investigated by a variety of techniques (WAXS, FT-IR, CP-MAS, TGA), in particular with respect to the semi-crystalline character of the polymer and its affinity toward water. The observed experimental features are rationalized on the basis of the ability for the macromolecular chains to associate via the pendant carboxylic acids, and of the high global symmetry obtained for this polyacid through the geminal placement of the side substituents. 


\section{INTRODUCTION}

Obtaining polymers with a strong predisposition to crystallize usually requires that a high symmetry be introduced into the chain structure. This constraint is exhibited by atactic polymers, such as polystyrene or polypropylene, which typically have difficulties in crystallizing while their tactic equivalents do not. Functional groups and their ability to interact in the crystal lattice is also of major help in the crystallization process. Since the seminal experimental work by Carothers and its team at the DuPont company in the early 1930's, it is well-known that increasing the tendency for polymer chains to interact with each other enhance dramatically the system's ability to crystallize and greatly raise the obtained melting points..$^{1-5}$ For example, aliphatic polyamides (nylons) have a much higher inclination to crystallize than their polyester analogs, the melting points in this case increasing with the density of the secondary carboxamide $-(\mathrm{C}=\mathrm{O})-\mathrm{NH}-$ groups located in the backbone at regular intervals.

It is widely accepted that the above general principles hold true for most - if not all - polymer structures, and they are indeed very valuable when designing new crystalline polymers with tailor-made properties. Yet, among the many possible self-associating building blocks that could be envisioned in order to obtain high levels of complementarity and strongly attractive interactions between adjacent chains in the crystal lattice, one obvious moiety - carboxylic acid - has currently not attracted much attention. Like carboxamides though, carboxylic acids are both hydrogen donors and acceptors in hydrogen bonding processes (Scheme 1). As a result, they are capable of interacting with each other to yield either cyclic dimers such as $\mathbf{A}$ or oligomeric structures B. In organic crystals, one usually finds the dimeric structure for carboxylic acids, while both types of structure typically co-exist in solution. ${ }^{6-9}$ The strength of the hydrogen bonds depends upon several factors such as the local polarity and the relative difficulty 
in reaching optimal geometries. In non-polar solvents such as carbon tetrachloride, the dimerization binding constant to A-type structures is slightly higher for aliphatic carboxylic acids vs. the corresponding aliphatic carboxamides, although the formation of $\mathbf{B}$-type oligomers is slightly favored for the carboxamides. ${ }^{10}$

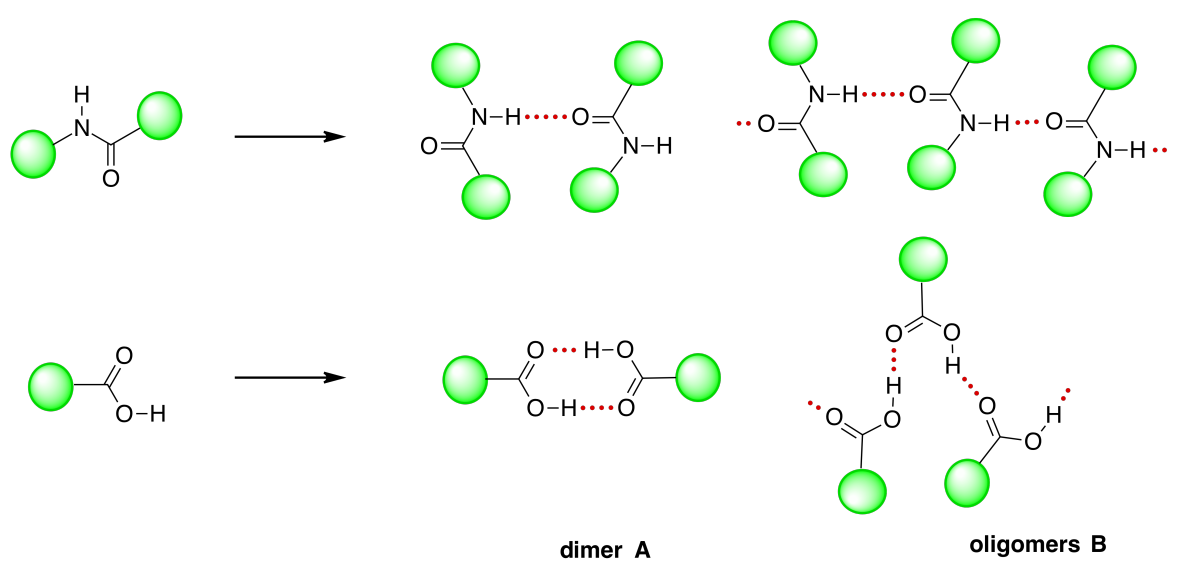

Scheme 1. Self-association processes and structures obtained for hydrogen-bonding units such as secondary amides or carboxylic acids.

Contrary to secondary carboxamides whose location is usually in the polymer backbone, carboxylic acids can obviously only be introduced in the polymer structure as side substituents. The most common occurrence is in poly(meth)acrylic acids where the acid groups are located on every second carbon of the backbone chain, but polyacids based on other repeat units have been described as well such as poly(maleic acid), polyitaconic acid or other $\alpha$-substituted polyacrylic acids to name just a few. ${ }^{11}$ Despite the already large number of investigated polyacid structures, to the best of our knowledge, only one report dealing with isotactic polyacrylic acid has currently demonstrated that a semi-crystalline polymer can be obtained. ${ }^{12}$ This small occurrence results likely from the fact that most polyacids described so far have their carboxyl function located at a 
pseudochiral position along the chain and are therefore capable of generating a tacticity. Yet they have mainly been obtained and characterized in their atactic form, i.e. in a geometry that impedes the crystallization process. As a result, one obvious way to increase the number of semicrystalline acid-based polymers would thus be to design synthetic routes to tactic equivalents of the already described atactic polyacids.

Another possible approach would be to eliminate the tacticity issue from the very outset, and target polymeric structures displaying a plane of symmetry along the chain. This second method that leads to polymers with no tacticity was privileged in the work described in this contribution, taking advantage of our previous success in obtaining poly(dialkyl trimethylene-1,1dicarboxylate) polymers $\left(\mathrm{CH}_{2}-\mathrm{CH}_{2}-\mathrm{C}(\mathrm{COOR})_{2}\right)_{\mathrm{n}}$, a fully symmetrical polymer having two ester groups on every third carbon alongside a polymethylene chain. ${ }^{13-17}$ We recently described its hydrolysis to various inorganic salt that exhibited unusual solution properties such as the full insolubility of the sodium salt. ${ }^{18-19}$ In this contribution are described and discussed the properties of the corresponding $\left(\mathrm{CH}_{2}-\mathrm{CH}_{2}-\mathrm{C}(\mathrm{COOH})_{2}\right)_{\mathrm{n}}$ polyacid, as well as an improved procedure to obtain it. The full synthetic approach is summarized in Scheme 2. 
a)

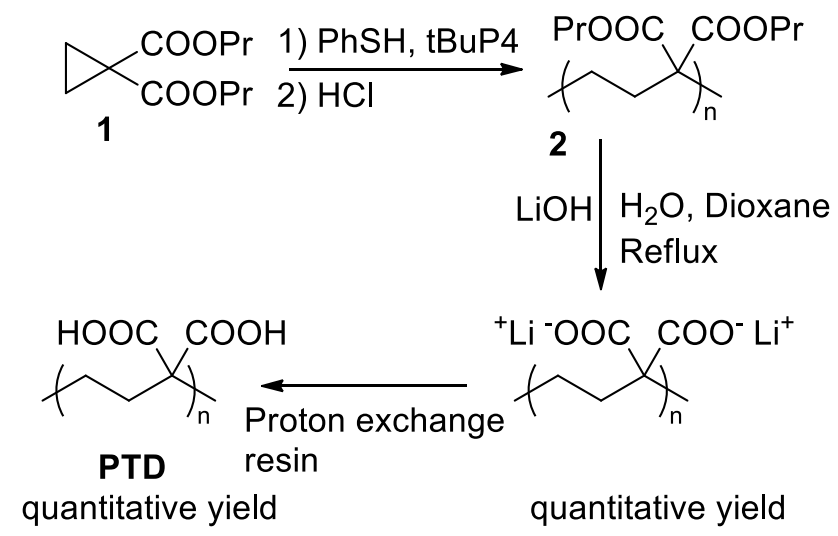

b)

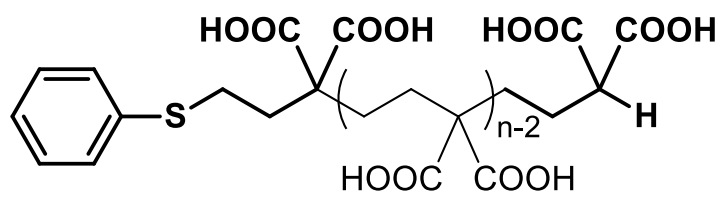

Scheme 2. Structure of poly(trimethylene-1,1-dicarboxylic acid) (PTD) and synthetic scheme used to obtain it: (a) three-step procedure based on the living ring-opening polymerization of din-propyl cyclopropane-1,1-dicarboxylate, basic hydrolysis of the pendant esters, and reacidification; (b) full structure of the obtained polymer, including the end-groups (in bold) resulting from the controlled initiation and termination steps.

\section{EXPERIMENTAL SECTION}

Materials. Monomer 1 (di- $n$-propyl cyclopropane-1,1-dicarboxylate) and poly(di- $n$-propyl trimethylene-1,1-dicarboxylate) $\mathbf{2}$ were synthesized according to previously described methods. ${ }^{13,19}$ Lithium hydroxide monohydrate (98\%, Aldrich), 1,4-dioxane (99\%, Carlo Erba), THF (99\%, stabilized with BHT, Carlo Erba), chloroform (99\%, VWR), acetone (99\%, Aldrich), DMF (99\%, Aldrich), DMSO (99.5\%, VWR), ethanol (96\%, Aldrich), methanol (technical grade, Aldrich), isopropanol (pure, Aldrich), formamide (99\%, Aldrich), N-methyl formamide 
(99\%, Aldrich) and N-methyl pyrrolidone (99.5\%, Aldrich) were used as received. The protonexchange resin Amberlite ${ }^{\circledR}$ IR 120 hydrogen form (Aldrich) was regenerated prior to use (see below).

Instrumentation. Solutions of polymers were freeze-dried on a CHRIST ALPHA 1-2 LD plus lyophilizer. Thermal degradations were investigated using a Setaram Setsys Evolution 16 instrument (TGA) or a Setaram Labsys ${ }^{\mathrm{TM}}$ Evo instrument (argon, 1.6 bar). The single DSC (Differential Scanning Calorimetry) measurement was carried out using a Diamond DSC (Perkin-Elmer) calibrated with indium standards (nitrogen purge at $20 \mathrm{~mL} \cdot \mathrm{min}^{-1}$ ).

FT-IR spectra were recorded on a TENSOR 27 Bruker spectrometer equipped with an ATR Digi Tect DLATGS detector (32 scans, $4 \mathrm{~cm}^{-1}$ resolution) in the 500-4,000 $\mathrm{cm}^{-1}$ range. ${ }^{1} \mathrm{H}$ and ${ }^{13} \mathrm{C}$ NMR spectra were recorded on a Bruker Avance II spectrometer operating at resonance frequencies of 400 and $100 \mathrm{MHz}$, respectively. Spectra were referenced based on the NMR solvent chemical shift(s). ${ }^{13} \mathrm{C}$ CP-MAS (Cross Polarization-Magic Angle Spinning) solid-state NMR measurements were conducted at room temperature on a Bruker Advance III 400 NMR equipped with a MAS solid-state probe and a MAS II module. Chemical shift referencing was performed using adamantane. The Igor Pro 6.37 software (WaveMetrics, Inc., Portland, Oregon) was used for ${ }^{13} \mathrm{C}$ solid-state spectra peak deconvolution. A combination of Lorentzian and Gaussian fits was applied on narrow and large peaks, respectively, which ensured a correct mathematical fit of the spectra. Samples were introduced in $\mathrm{ZrO}_{2} 4-\mathrm{mm}$ rotors, and spun at $6 \mathrm{kHz}$ at room temperature, recording $13 \mathrm{k}$ scans per sample. X-ray diffraction patterns were collected with a Panalytical X'Pert Pro diffractometer equipped with an X'celerator rapid detector, using a cobalt radiation source. Polarized light microscopy images were obtained at room temperature on an Olympus BX-50 microscope. 
Size Exclusion Chromatography (SEC) experiments were performed in chloroform (1.0 $\mathrm{mL} \cdot \mathrm{min}^{-1}$ ) at room temperature, using a Spectra Physics P100 pump, and two PLgel Polymer Laboratories linear columns $\left(5 \mu \mathrm{m}\right.$ Mix-C, separation range: 200 to $\left.2 \times 10^{6}\right)$. A Wyatt Technology Optilab Rex interferometric refractometer (690 nm laser) and a Wyatt Technology Minidawn light scattering photometer (three-angle detection, $20 \mathrm{~mW}$ semiconductor laser (690 nm)) were used as detectors.

Dynamic Light Scattering (DLS) measurements were obtained at a $173^{\circ}$ angle with a Nano-ZS Zetasizer from the Malvern company, equipped with a $4 \mathrm{~mW}$ He-Ne laser at $633 \mathrm{~nm}$. Measurements were obtained in triplicate (each measurement was the average of fifteen $10 \mathrm{~s}$ runs). Obtained data were analyzed using Malvern Zetasizer Series Software version 7.11.

Sample Preparation. The hydrated polymers were dried using a Büchi glass oven B-585 under moderate vacuum $(\sim 30 \mathrm{mbar})$ at $50^{\circ} \mathrm{C}$. Attempts to obtain thin polymer films on a glass slide were based on a Chemat Technology spin coater KW-4A, using a solution of polymer in formamide $\left(2.0 \mathrm{~g} . \mathrm{L}^{-1}\right)$, or on a multiple evaporation process of aqueous polymer solutions using a procedure described for isotactic polyacrylic acid. ${ }^{12}$

Synthesis of Poly(trimethylene-1,1-dicarboxylate) Lithium Salt. In a typical experiment, $2.000 \mathrm{~g}$ ( $18.7 \mathrm{mmol}$ ester) of poly(di- $n$-propyl trimethylene-1,1-dicarboxylate) $\mathbf{2}$ is dissolved in $100 \mathrm{~mL}$ of 1,4-dioxane in a round bottom glass under magnetic stirring. A solution of $2.120 \mathrm{~g}$ of LiOH. $\mathrm{H}_{2} \mathrm{O}$ in $20 \mathrm{~mL}$ of distilled water is then added to the reaction medium (leading to a white trouble in the solution). The mixture is heated at reflux overnight. The solvents are evaporated, and the resulting white solid dissolved in $25 \mathrm{~mL}$ of distilled water and precipitated in methanol. The obtained solid is dried under vacuum at $60^{\circ} \mathrm{C}$, yielding $1.305 \mathrm{~g}(18.4 \mathrm{mmol}$ carboxylate $)$ of a white powder (quantitative yield). 
Preparation of the Acidic Ion-Exchange Resin. $20.0 \mathrm{~mL}$ (2 equivalents per carboxylate group; 1.8 eq. $\mathrm{L}^{-1}$ ) of Amberlite IR120 in its hydrogen form were added to an aqueous solution of $\mathrm{HCl}\left(60.0 \mathrm{~mL}, 1.95 \mathrm{~mol} . \mathrm{L}^{-1}\right)$, stirred at room temperature for half an hour, and filtrated. The obtained resin was washed with distilled water until a neutral $\mathrm{pH}$ was obtained.

Synthesis of Poly(trimethylene-1,1-dicarboxylic acid) PTD. The above hydrated resin was added to a solution of $1.305 \mathrm{~g}$ (18.4 mmol carboxylate) of the polyelectrolyte salt in $50 \mathrm{~mL}$ of water, stirred for 2 hours at room temperature, and filtrated. The resin was washed twice with 10 $\mathrm{mL}$ of water to remove any adsorbed polymer. The obtained aqueous solution was then freezedried, yielding $1.180 \mathrm{~g}$ of a white powder (quantitative yield).

Direct Acid Hydrolysis. Solid poly(di- $n$-propyl trimethylene-1,1-dicarboxylate) 2 (1.5 g, $1.4 \times 10^{-2}$ mol equivalents) is introduced in a round-bottom flask, and concentrated sulfuric acid $(96 \%, 15.0 \mathrm{~mL}, 30 \mathrm{~mol}$ equivalents) is added dropwise to the polymer. Once the addition is complete, the solution is maintained at $45^{\circ} \mathrm{C}$ for 24 hours. The solution turns progressively brown, then dark red. The medium is diluted with $100 \mathrm{~mL}$ water, then dialyzed against water for 2 days. The recovered solution is freeze-dried, $350 \mathrm{mg}$ of a brownish powder being recovered (yield : 38\%).

Water Vapor Sorption Studies. Water uptake of solid polyacid samples were measured gravimetrically at fixed relative humidities and temperatures using a home-built controlled humidity chamber inspired from the literature. ${ }^{20-21}$ It was made from a small commercial borosilicate glass dessicator with a closely attached lid (see Scheme 3), on whose bottom a small cylindrical vessel (A) containing a saturated aqueous solution of a specific inorganic salt was positioned. An excess of inorganic salt was added to the saturated solution to ensure that saturation is maintained in the whole range of investigated temperatures. The sample was 
carefully weighted in a plastic weighting dish (B) whose diameter was selected in order to be lower than the diameter of the upper section of the desiccator and larger than the diameter of the lower section. Those dimensions allow the investigator to carefully place the dish and its solid content just above the saturated solution in a stable position. In order to facilitate the transfer of the weighting dish in and out of the desiccator and to the analytical balance, two small holes were drilled on opposite sides of the plastic dish, and a curved copper wire was attached to act as a handle. The desiccator was immerged in a thermostated water bath (Julabo ME F5) and covered on its top with an isothermal vermiculite cover. $\mathrm{K}_{2} \mathrm{SO}_{4}, \mathrm{KBr}, \mathrm{NaCl}$ and $\mathrm{Mg}\left(\mathrm{NO}_{3}\right)_{2}$ salts were used to generate fixed relative humidities using the equilibrium data compiled by the National Bureau of Standards. ${ }^{22}$ Weighting measurements were carried out with an analytical balance until a constant weight was obtained. Special care was exercised when water uptake values were found to be very sensitive to the temperature or relative humidity as small variations in the immersion depth of the humidity chamber in the bath or inefficient placement of the isothermal cover could result in systematic errors.

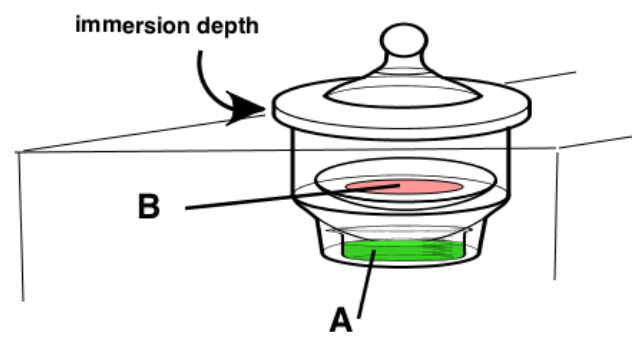

Scheme 3. Schematic drawing of the homemade water sorption cell used in this study (A: saturated aqueous solution of an inorganic salt specifically selected to generate a controlled relative humidity, B: polyacid sample in a plastic weighting dish). 


\section{RESULTS AND DISCUSSION}

PTD Synthesis and Structural Analysis. The lithium salt of PTD, $\left(\mathrm{CH}_{2}-\mathrm{CH}_{2}-\mathrm{C}(\mathrm{COOLi})_{2}\right)_{\mathrm{n}}$, had been previously obtained by hydrolyzing poly(di-n-propyl trimethylene-1,1-dicarboxylate) 2 with lithium hydroxide in a mixture of water and dioxane at reflux (see Scheme 2). ${ }^{18}$ In order to optimize this reaction, it was monitored in situ by IR spectroscopy, using an ATR diamond immersion probe and focusing on three signals: the $\mathrm{C}=\mathrm{O}$ vibration band for the ester at $1721 \mathrm{~cm}^{-}$ ${ }^{1}$, a very strong band progressively appearing at $1566 \mathrm{~cm}^{-1}$, and the $\mathrm{C}-\mathrm{O}$ vibration of the esters at $1197 \mathrm{~cm}^{-1}$ (Figure 1a and Figure S1 in the Supporting Information). The signal at $1721 \mathrm{~cm}^{-1}$ was partly obscured by the water vibration band present at $1643 \mathrm{~cm}^{-1}$, but the overall trend for this band intensity (after subtraction of the initial spectrum) was identical to those for the two other bands, suggesting the subtraction of the strong water band was efficient enough for a quantitative analysis to be performed. Yet, the much stronger band at $1566 \mathrm{~cm}^{-1}$, which was assigned to the very strong and characteristic asymmetric stretching of the expected $\mathrm{COO}^{-}$group, ${ }^{23}$ was found to be much easier to use as a quantitative marker of the reaction course (see Figure 1b). 
(a)

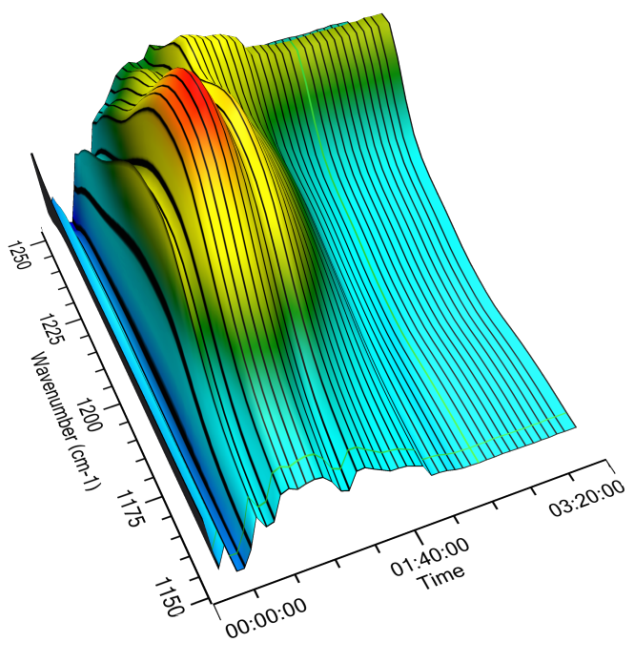

(b)

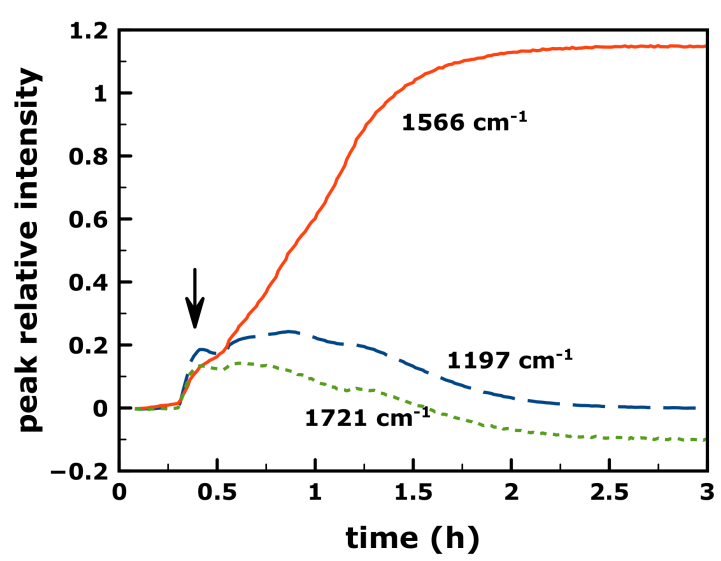

Figure 1. (a) 3-D IR plot (wavenumber and signal intensity vs. time) in the $1150-1250 \mathrm{~cm}^{-1}$ range for the monitoring of poly(di- $n$-propyl trimethylene-1,1-dicarboxylate) 2 hydrolysis with $\mathrm{LiOH}$ in a water/dioxane mixture $\left(0.435 \mathrm{~g}\right.$ of 2 and $0.500 \mathrm{~g}$ of $\mathrm{LiOH}_{\mathrm{H}} \mathrm{H}_{2} \mathrm{O}$ in $20.0 \mathrm{~mL}$ of dioxane and $5.0 \mathrm{~mL}$ of water at reflux); (b) Evolution of three signals at 1721 (green line, $\cdots$ ), 1566 (red line, - - ) and 1197 (blue line, - - -) $\mathrm{cm}^{-1}$, respectively (the starting time coincides with the introduction of the lithium hydroxide aqueous solution in the 2 /water/dioxane mixture while the arrow indicates that the heterogeneity introduced in the clear solution when adding the hydroxide has mostly disappeared). The signal intensity was modified by subtracting the initial spectrum recorded 2 minutes after the starting time.

For an initial period of about 20 minutes (whose end is marked by an arrow on Figure 1b), no IR signal evolution could be monitored. This step corresponds roughly to the visual appearance of a cloudiness in the solution mixture that started when the basic water solution, a non-solvent of $\mathbf{2}$, was added to the initially clear polymer solution. It is hypothesized that some solid particles start adhering to the probe at this point, preventing further monitoring of events in the suspension. This conjecture is supported by the fact that a normal observation of the IR bands 
and their evolution over time resumed right after a clarification of the solution was observed, i.e. after roughly 20 minutes. We submit that partly hydrolyzed polymers that had accumulated at this stage, containing both unreacted ester groups and carboxylate anion moieties, started acting as a surfactant and helped in solubilizing unreacted $\mathbf{2}$. Whatever the final explanation for this observation, IR proved to be an excellent tool to oversee the final stage of the reaction, with a plateau clearly observed for all three monitored signals after $2.5 \mathrm{~h}$.

Acidification of the recovered lithium polyelectrolyte was obtained by simply adding beads of a strong-acid $\left(\mathrm{SO}_{3} \mathrm{H}\right)$ resin to a solution of the polymer, filtering the beads, and freeze-drying the supernatant. The obtained yield was quantitative. The above procedure was successfully tested on precursor polymers $\mathbf{2}$ of degrees of polymerization up to 200, with no influence on the yield nor on the structure of the obtained polyacid.

2 could also be hydrolyzed under acidic conditions, by heating a solution $\left(0.1 \mathrm{~g} \cdot \mathrm{mL}^{-1}\right)$ in concentrated $96 \%$ sulfuric acid at $45^{\circ} \mathrm{C}$ for $24 \mathrm{~h}$. The ${ }^{1} \mathrm{H}$ NMR spectrum of the recovered polymer was identical to that of the polymer obtained under basic hydrolysis (see below), although the yield was lower (38\% vs. 100\%) due to the difficulties experienced when lyophilizing the solution. In addition, the polymer was slightly brownish in color and not white.

Structural characterization of the polyacid was achieved by NMR and FT-IR spectroscopies, as well as by TGA (for determining the amount of bound water). ${ }^{13} \mathrm{C} \mathrm{NMR}$ required long accumulation time due to the low solubility of PTD in classical NMR solvents such as water or DMSO (see below). Three signals can be observed in $\mathrm{D}_{2} \mathrm{O}$ at 26.4, 56.9 and $174.8 \mathrm{ppm}$ (acetone insert, using the $\mathrm{CH}_{3}$ signal at $29.8 \mathrm{ppm}$ for calibration), the $26.4 \mathrm{ppm}$ peak being a little broader than the two other ones (Figure S2 in the Supporting Information). They could be assigned to the $\underline{\mathrm{CH}}_{2}, \underline{\mathrm{C}}(\mathrm{COO})_{2}$ and $\underline{\mathrm{COO}}$ fragments, respectively. 
The much higher sensitivity of ${ }^{1} \mathrm{H}$ NMR compared to ${ }^{13} \mathrm{C}$ NMR allows for the detection of signals arising from chemical functionalities present in the polymer at a much lower concentration than those located in the main chain (i.e., end groups and structural defects). Samples of 2 used in this study had indeed been obtained by polymerizing di- $n$-propyl cyclopropane-1,1-dicarboxylate according to the $\mathrm{XH}-\mathrm{Bu}^{\mathrm{t}} \mathrm{P}_{4}$ method,${ }^{13}$ using thiophenol as the coinitiator and aqueous $\mathrm{HCl}$ as the terminating agent. This published technique yields polymers of very narrow molecular weight distributions and controlled degrees of polymerization, bearing specific X-end-groups at one end, here a thiophenyl moiety, and a proton at the other end due to the use of $\mathrm{HCl}$ as the terminating agent. ${ }^{13-14}$ The structure for both expected end-groups is schematically provided in Scheme $2 \mathrm{~b}$. As the hydrolysis reaction is not expected to affect the structure of the polymer backbone, the same end-groups as the ones initially present on $\mathbf{2}$ should be observable. The ${ }^{1} \mathrm{H}$ NMR spectrum of a sample of 2 in $\mathrm{D}_{2} \mathrm{O}$ confirms this hypothesis. As can be seen in Figure 2, a large peak corresponding to the magnetically identical $\mathrm{CH}_{2}$ protons present in the backbone can be observed at $1.5 \mathrm{ppm}$. In addition, small signals can also be seen in between 7.15 and $7.40 \mathrm{ppm}(\mathbf{A})$, as well as at $2.97(\mathbf{B}), 2.79(\mathbf{C})$ and $2.03(\mathbf{D}) \mathrm{ppm}$. The first set of signals (A) is clearly associated to the aromatic protons of the phenylthio end-group. The same intensity ratio of 2:2:1 along with the same peak pattern can also be found in a model molecule such as phenylthioethane, corresponding to the meta, ortho and para protons, respectively. ${ }^{24}$ If an integration level of 5 is used for $\mathbf{A}$ (due to five aromatic protons), the number of protons for $\mathbf{B}, \mathbf{C}$ and $\mathbf{D}$ can be rounded up to 1, 2 and 3, respectively, although an accurate value for $\mathbf{D}$ is difficult to obtain due to a non-flat baseline in its vicinity, meaning that a lower value of 2 could also be envisioned. The triplet for $\mathbf{B}$ can be assigned to the malonic proton $\mathrm{C} \underline{\mathrm{H}}(\mathrm{COOH})_{2}$, and the broad $\mathbf{C}$ peak to the $\mathrm{PhS}-\mathrm{C}_{2}-\mathrm{CH}_{2}$ protons. A direct assignment for $\mathbf{D}$ is 
not straightforward, but a COSY NMR experiment (Figure S3 in the Supporting Information) unambiguously indicates that it originates from the $\mathrm{PhS}-\mathrm{CH}_{2}-\mathrm{C}_{2}$ protons. It should be noted that the average degree of polymerization can be directly obtained from a comparison between the integration for the $\mathbf{A}, \mathbf{B}, \mathbf{C}$ or $\mathbf{D}$ peaks with the large main signal at $1.5 \mathrm{ppm}$. A value of 50 can be measured for the sample whose spectrum is depicted in Figure 2, in perfect agreement with the degree of polymerization obtained by SEC-MALLS for the polymeric ester precursor 2. This finding and the absence of other small signals in the spectrum corroborate the efficiency and cleanliness of the hydrolysis reaction, as no side reactions do appear to affect the polymer backbone, nor the side groups. Unfortunately, the low solubility of PTD in water made any aqueous SEC characterization impossible, while a SEC analysis in formamide was technically impossible in our laboratory.
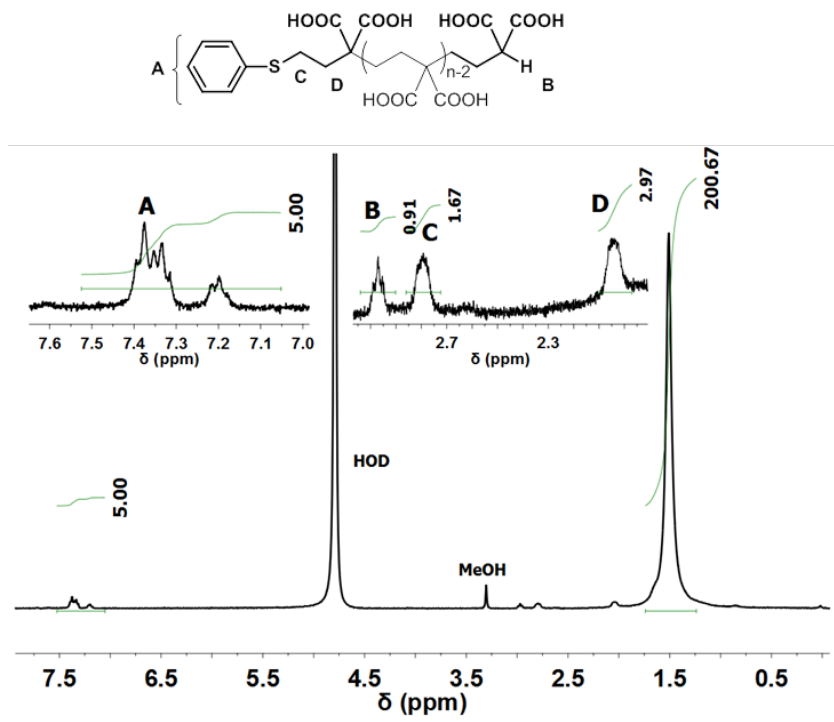

Figure 2. ${ }^{1} \mathrm{H}$ NMR spectrum of PTD in $\mathrm{D}_{2} \mathrm{O}$ (spectrum calibrated by using the HOD signal at $4.7 \mathrm{ppm})$. 
A typical TGA thermogram under argon is provided in Figure 3 for a sample recovered directly from the freeze-drying of a polyacid solution in water. A putative assignment of the consecutive degradation steps is also provided on the thermogram. A first weight loss in the 90$130^{\circ} \mathrm{C}$ range is associated to the amount of free or bound water present in the polymer. This experimental approach was used during the investigation of samples submitted to several wetting processes (see below) to check their water content. A complete analysis of the thermal decomposition of PTD (kinetics, structure of the products...) will be provided in two upcoming papers.

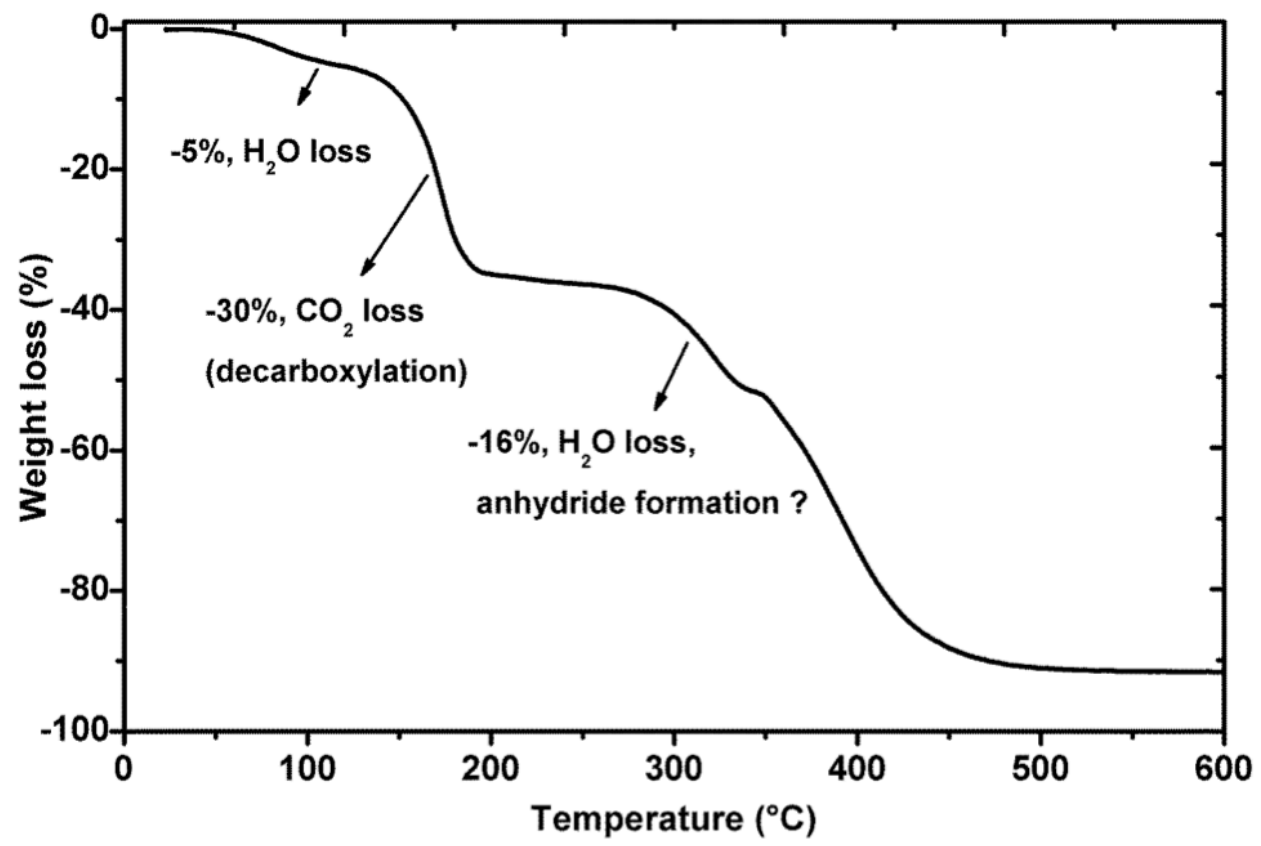

Figure 3. TGA thermogram of a PTD sample directly recovered from the freeze-drying flask (argon, heating rate of $10 \mathrm{~K} \cdot \mathrm{min}^{-1}$ ).

Solubility of PTD in Water and Organic Solvents. The samples of 2 investigated in this study (and all subsequent physicochemical investigations in this contribution) had a degree of polymerization of 50 and a very narrow distribution of molecular weights $(<1.10)$. In water, 
their solubility - as determined by the filtration of a saturated solution maintained at $25^{\circ} \mathrm{C}$ for 4 days to reach equilibrium, lyophilization of the filtrate and weighting of the residue - was of 0.8 wt-\% (duplicate measurements). As a comparison, aqueous solutions of up to 63 wt- $\%$ polyacrylic acid can be commercially purchased, indicating that PTD is less soluble by almost two orders of magnitude.

The water sample recovered after filtration at $25^{\circ} \mathrm{C}$ was turbid, and remained turbid even after filtration over a cellulose membrane of $0.20 \mu \mathrm{m}$ pore size. A dynamic light scattering (DLS) experiment indicated that particles were indeed present in the solution, but their size distribution was too broad and polymodal to release a reliable estimate of the average size. The raw autocorrelation data are provided in the Supporting Information (Figure S4). Heating the suspension at $70^{\circ} \mathrm{C}$ led to a disappearance of the DLS signal and a clarification of the solution to the naked eye. A return of the temperature back to $25^{\circ} \mathrm{C}$ did not induce a precipitation, even after 4-5 weeks. The above results suggest that conditions can be obtained to self-assemble 2 in water solution, leading to aggregates, a feature that had always been observed for some polyacids such as tactic poly(methacrylic acids). ${ }^{25}$ It is also reminiscent of the behavior observed for biopolymers such as alginic acid whose crystalline blocks, when present, induce the formation of gels at low $\mathrm{pH}$ via crystallization-driven self-assembly. ${ }^{26-28}$

Solubility in organic solvents (Tables 1 and 2) is also very low. PTD samples solubilize slightly in highly polar solvents such as DMF or DMSO at room temperature, and are not soluble at all in THF or in methanol. In sharp contrast again, polyacrylic acid is reasonably soluble in methanol, ethanol, THF, DMF or DMSO. Attempts to modify the temperature did not genuinely affect the results. A progressive clarification of the starting PTD-solvent suspension could be visualized above $100^{\circ} \mathrm{C}$ in solvents such as $\mathrm{N}$-methyl-2-pyrrolidone, DMSO, DMF and water, 
but it originates mostly - if not completely - from the induced thermal decarboxylation of the polymer under these conditions. This decarboxylation reaction is currently under further study in our group.

The only two good solvents that led to room temperature solubilization were formamide and $\mathrm{N}$-methyl formamide. As little data is available in the literature on polymer solutions made from these polar but unusual solvents, it is not clear whether the observed much better solubility of PTD in these liquids with respect to water apply to other polymers as well. The only solventrelated physicochemical parameter we could identify that correlates qualitatively with the ability for the solvent to dissolve the polymer was the dielectric constant. This trend can be visualized in Table 1 where one can see that the dielectric constants of non-solvents are roughly lower than 25-30, those for the only two good solvents (formamide and N-methyl formamide) are higher than 100 , with the intermediate solvents included between 30 and 80 . It must be noted that the dielectric constant is the only parameter that predicts a higher solvation power for formamide and N-methyl formamide than for water. All other empirical solvent polarity scales for which polarity single parameters have been determined for both formamide and water (i.e., Reichardt $E_{T}^{N}$, Grunwald-Winstein's $Y$, Berson $\Omega$, Kosower $Z$, Browstein $S$, Dubois-Goetz-Bienvenüe $\Phi$, and Dimroth-Reichardt $\left.E_{T}(30)\right)$, always include water at the top. ${ }^{29}$ 
Table 1. Solubility of PTD in several traditional solvents, arranged from top to bottom as a function of their polarity ${ }^{\mathrm{a}}$

\begin{tabular}{|c|c|c|c|}
\hline solvent & $\begin{array}{l}\text { solvent dielectric } \\
\text { constant }^{\text {b }}\end{array}$ & $\begin{array}{c}\text { Solubility at } \\
\text { room temperature }\end{array}$ & $\begin{array}{l}\text { influence of the } \\
\text { temperature }^{d}\end{array}$ \\
\hline 1,4-dioxane & 2.21 & - & $-\left(\right.$ up to $\left.101^{\circ} \mathrm{C}\right)$ \\
\hline chloroform & 4.89 & - & - (up to $\left.61^{\circ} \mathrm{C}\right)$ \\
\hline acetic acid & $6.17\left(20^{\circ} \mathrm{C}\right)$ & - & $-\left(\right.$ up to $\left.118^{\circ} \mathrm{C}\right)$ \\
\hline $\mathrm{THF}$ & 7.58 & - & - (up to $\left.66^{\circ} \mathrm{C}\right)$ \\
\hline pyridine & 12.91 & - & $-\left(\right.$ up to $\left.115^{\circ} \mathrm{C}\right)$ \\
\hline isopropanol & 19.92 & - & - (up to $\left.82^{\circ} \mathrm{C}\right)$ \\
\hline acetone & 20.56 & - & $-\left(\right.$ up to $\left.56^{\circ} \mathrm{C}\right)$ \\
\hline ethanol & 24.55 & - & $-\left(\right.$ up to $\left.78^{\circ} \mathrm{C}\right)$ \\
\hline N-methyl-2-pyrrolidone & 32.20 & $+/-$ & ambiguous \\
\hline methanol & 32.66 & - & not determined \\
\hline DMF & 36.71 & $+/-$ & ambiguous $^{\mathrm{e}}$ \\
\hline DMSO & 46.45 & $+/-$ & ambiguous $^{\mathrm{e}}$ \\
\hline water & 78.36 & $+/-(0.8 w \mathrm{t}-\%)$ & ambiguous $^{\mathrm{e}}$ \\
\hline formamide & 109.50 & + & not determined \\
\hline N-methyl formamide & 182.40 & + & not determined \\
\hline \multicolumn{4}{|c|}{$\begin{array}{l}\text { as evaluated according to the dielectric constant (relative permittivity) of the neat liquid } \\
\text { olvent at } 25^{\circ} \mathrm{C} \text {, unless indicated (see text); }{ }^{\mathrm{b}} \text { literature values }{ }^{29} \text {; }{ }^{\mathrm{c}} \text { for a polymer initial } \\
\text { concentration of } 10 \mathrm{~g} \cdot \mathrm{L}^{-1} \text {, the following observations could be made after } 2 \text { hours: + clear } \\
\text { olution, +/- suspension, - precipitation; }{ }^{\mathrm{d}} \text { a test tube containing the initial solution/suspension } \\
\text { vas plunded in a water bath whose temperature wad rapidly raised from room temperature to the } \\
\text { ooiling point of the solvent; }{ }^{\mathrm{e}} \text { at these temperatures, decarboxylation can possibly occur. }\end{array}$} \\
\hline
\end{tabular}

Formamide and $\mathrm{N}$-methyl formamide are not very convenient solvents for further modification reactions as most organic reagents are not soluble in them. Attempts to identify solvent mixtures based on formamide that would be more "lipophilic" are summarized in Table 2. The amount of formamide required to solubilize PTD suspensions in water, DMSO, pyridine and dioxane, respectively, is indicated, with a total failure observed for the dioxane suspension. It is interesting to note that, for the two full non-solvents (pyridine and dioxane), pyridine with a dielectric constant of about 13 only required 43 wt- $\%$ of formamide while dioxane with a lower dielectric constant of about 2 could not be turned into an acceptable PTD co-solvent by adding formamide. 
Table 2. Co-solvent composition that fully clarify the suspension when adding dropwise neat formamide to suspensions of PTD in several non-solvents at $20^{\circ} \mathrm{C}^{\mathrm{a}}$

\begin{tabular}{|c|c|c|}
\hline non-solvent & $\begin{array}{l}\text { non-solvent dielectric } \\
\text { constant }^{\mathrm{b}}\end{array}$ & $\begin{array}{l}\text { composition of the solvent mixture } \\
\text { required to observe full solubilization } \\
\text { (wt-\%in formamide) }\end{array}$ \\
\hline water & 78.36 & 70 \\
\hline DMSO & 46.45 & 34 \\
\hline pyridine & 12.91 & 43 \\
\hline 1,4-dioxane & 2.21 & $100^{\mathrm{c}}$ \\
\hline
\end{tabular}

Solid-State Properties. PTD is a white solid that can be easily manipulated. Under mild experimental conditions (room temperature up to $30^{\circ} \mathrm{C}$, relative humidity lower than $50 \%$ ), any weight increase due to atmospheric water adsorption is slow, allowing sample weighting to be performed accurately without any special precautions.

Powder X-ray experiments (WAXS) performed on a lyophilized sample that contained 5 wt- $\%$ of water (according to TGA) indicated that the polymer is significantly crystalline (Figure 4). Well-defined diffraction peaks can be observed whose assignment has not been possible yet due to the lack of orientation. Attempts to obtain oriented semi-crystalline samples from aqueous solutions in order to acquire data on the local polymer structure in the crystal lattice have been unsuccessful thus far. Further efforts are still in progress, in combination with simulations using as precursor the diethyl ester polymer whose crystal structure is known. ${ }^{30}$

Films obtained by slow evaporation of either a saturated water solution or a 20 g.L $\mathrm{L}^{-1}$ formamide solution on a glass slide led to cracked films that were examined under a polarized light microscope (Figures S5-S7 in the Supporting Information). As expected from optically anisotropic crystalline materials, significant amounts of the solid exhibited birefringence. 
No specific melting peaks could be identified on DSC thermograms obtained by heating a PTD sample from room temperature to the decomposition temperature of $110^{\circ} \mathrm{C}$, suggesting that that the irreversible decomposition observed on the TGA occurs before the melting temperature has been be reached.

It must be noted that, to the best of our knowledge, only one carbon-chain polyacid, i.e. isotactic polymethacrylic acid, has ever been described to crystallize. ${ }^{12}$ We speculate that the inclination for PTD to easily crystallize originates from its high internal symmetry (i.e., full plane of symmetry with respect to the polymer backbone). The propensity of PTD to crystallize, which had already been observed for the ester precursors, ${ }^{30}$ is most probably the reason why low solubilities were observed for this polyacid (see above).

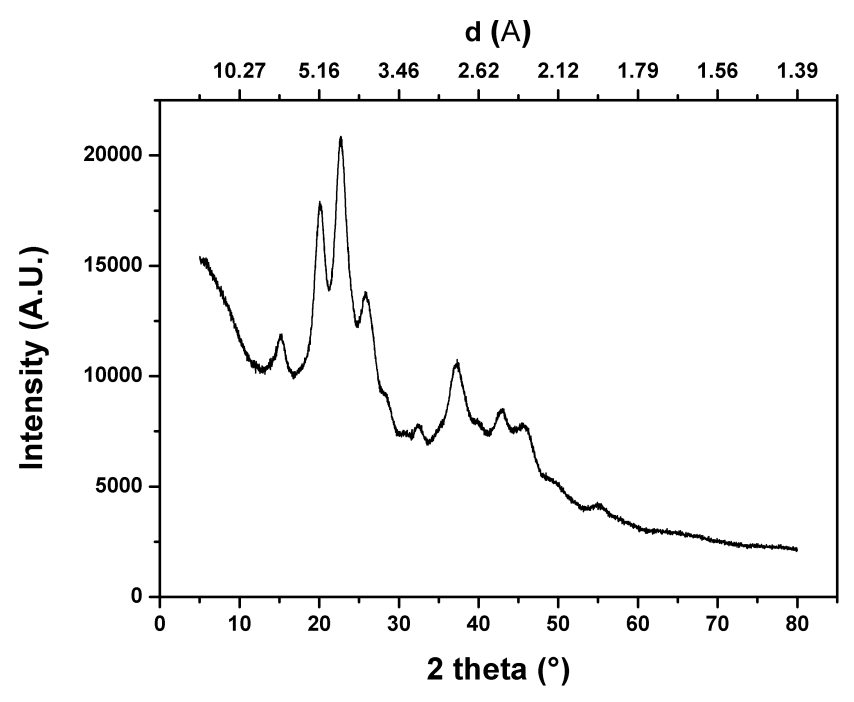

Figure 4. WAXS diffractogram of a PTD sample obtained after lyophilization of an aqueous polyacid solution (caution: the $2 \theta$ diffraction angles refer to a cobalt irradiation source; in order to facilitate possible comparisons with more traditional experiments using copper irradiation sources, interplanar distances $d$ calculated from the Bragg equation for $\mathrm{n}=1$ are provided on the upper $\mathrm{x}$ axis for selected $2 \theta$ values). 
Solid-state ${ }^{13} \mathrm{C}$ NMR measurements were carried out so as to investigate in further details the structural and morphological organization of PTD. Figure 5 shows the obtained CP-MAS ${ }^{13} \mathrm{C}$ spectrum, with the straightforward assignment of peaks highlighted on the figure. More attention was paid to peak 1 , which corresponds to the $-\mathrm{COOH}$ functional groups, as it is made of three separate peaks (see Figure 6). As described independently by Fortier-McGill and Asano for polymethacrylic acid (PMAA), ${ }^{31-32}$ the presence of multiple peaks for the carbonyl in carboxylic acid-containing polymers establishes the presence of local structural ordering.

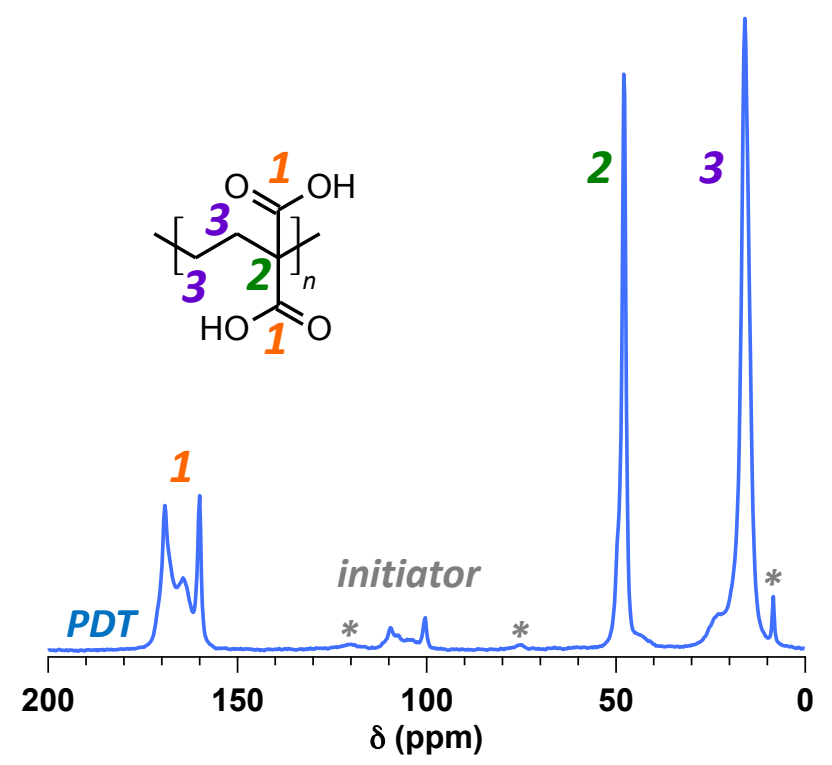

Figure 5. Solid-state CP-MAS ${ }^{13} \mathrm{C}$ NMR spectrum of PTD, along with the assignment for the individual peaks (signals indicated by an asterisk are spinning bands).

Based on the above NMR studies, the thinnest and most shielded peak (C in Figure 6) should correspond to the rigid regions in the polymer and therefore, due to PTD's semi-crystalline nature, to the crystal phase in the polymer. ${ }^{31-32}$ In order to unambiguously assign the three subpeaks in the carbonyl area to specific phases and chain arrangements, ${ }^{13} \mathrm{C} C \mathrm{CP}$-MAS spectra of dimethylmalonic acid $\left(\mathrm{CH}_{3}\right)_{2} \mathrm{C}(\mathrm{COOH})_{2}$, a crystalline model molecule for PTD repeat unit, and 
of an atactic sample of PMAA were recorded. The section of the spectra corresponding to the $\mathrm{COOH}$ functional group are displayed in Figure 6a, in comparison to PTD.
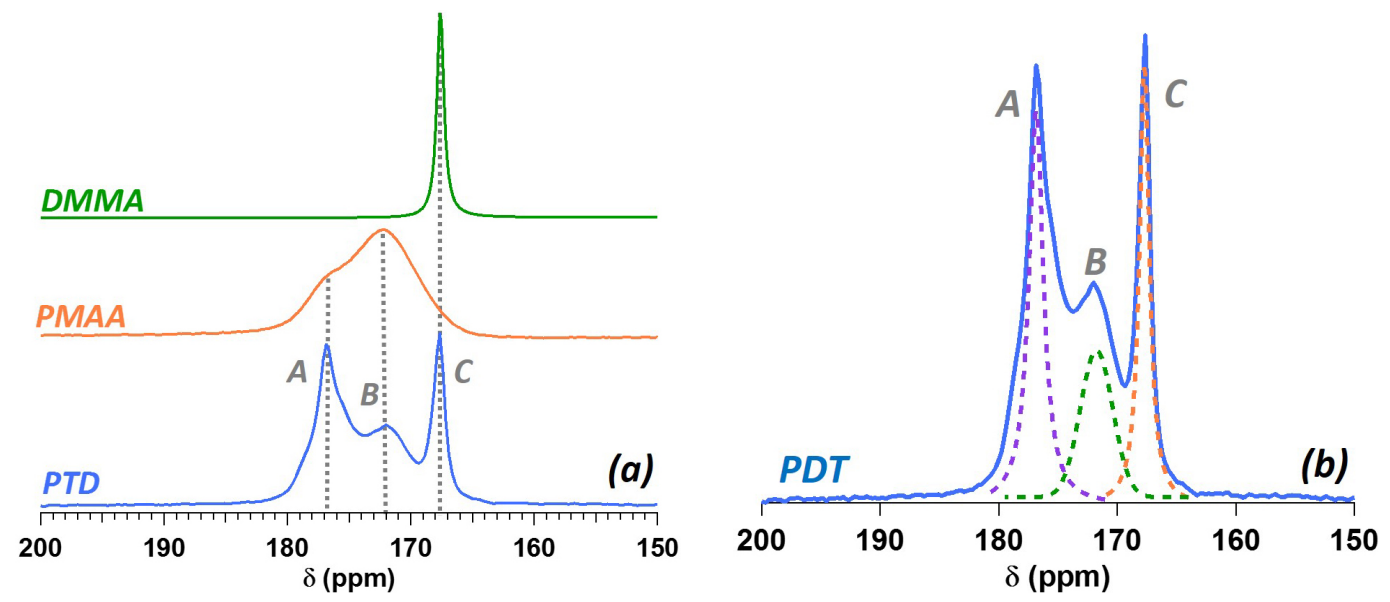

Figure 6. (a) From top to bottom: expansion of the $-\mathrm{COOH}$ signal observed by solid-state CPMAS ${ }^{13} \mathrm{C}$ NMR for dimethylmalonic acid (DMAA), atactic polymethacrylic acid (PMAA) and PTD; (b) peak fitting for the PTD spectrum: peak A was fitted with a Lorentzian equation $(\delta=$ $176.9 \mathrm{ppm}$, half-width $=1.64 \mathrm{ppm}), \mathrm{B}$ with a Gaussian equation $(\delta=171.8 \mathrm{ppm}$, half-width $=$ $3.23 \mathrm{ppm})$, and $\mathrm{C}$ with a Lorentzian equation $(\delta=167.7 \mathrm{ppm}$, half-width $=0.90 \mathrm{ppm})$.

This comparison validates the previous assumption that $\mathrm{C}$ corresponds to a crystalline fraction in the polymer, as the chemical shift and shape of $\mathrm{C}$ compares ideally with the single peak obtained for the fully crystalline DMAA. Furthermore, chemical shifts for peaks A and B fit nicely with atactic (i.e., amorphous) PMAA. Based on the assignment proposed by FortierMcGill and Asano for PMAA, ${ }^{31-32}$ peak A would relate to the carbon signature of loosely bound disorganized H-bonds (oligomers) between - $\mathrm{COOH}$ groups, whereas peak B would arise from $\mathrm{COOH}$ dimers bound in a cyclic structure. Such organizations are schematically drawn in Scheme 1. Based on the available X-ray structure determination for crystalline DMAA that indicates that all $\mathrm{C}(\mathrm{COOH})_{2}$ subunits participate to cyclic dimers ${ }^{33}$ and the very close fit for the 
${ }^{13} \mathrm{C}$ NMR COOH peaks of DMAA and PTD, respectively, it seems reasonable to assume that the dimeric structure is also to be found in the crystalline fraction.

The result of a mathematical deconvolution for the $-\mathrm{COOH}$ peak is shown in Figure 6b. From the respective areas, fractions for each type of organization could be estimated. It was found that the crystalline fraction (peak C) accounts for $25 \%$ of the total, while dimers (peak B) and oligomeric $\mathrm{COOH}$ (peak A) in the amorphous phase account for $27.5 \%$ and $47.5 \%$, respectively. The relative amount of dimers in the amorphous phase (about one-third of the total) is lower than in PMMA where the dimer-to-oligomer ratio is roughly inverse, and favors the formation of dimers over H-bonded oligomers.

Water Sorption Studies. The significant interaction of gaseous water with hydrogen-bonding solid polymers is a well-known phenomenon that can dramatically affect properties in the solid state. ${ }^{34}$ For instance, significant moisture uptake corresponding to weight increases of up to 40$50 \%$ have been observed for atactic polyacrylic acid at high relative humidities (Figure 7). ${ }^{34-37}$ In order to enable a fair comparison between polyacid $\mathbf{2}$ and polyacrylic acid, water sorptions at equilibrium were measured for 2 at 25 and $35^{\circ} \mathrm{C}$ in the $50-99 \%$ relative humidity range where significant water uptake take place for polyacrylic acid. The measurement were made gravimetrically and confirmed by TGA.

As can be seen in Figure 7, 2 displays approximately the same quantitative behavior as polyacrylic acid with respect to water adsorption, the crystallinity clearly not displaying any influence. 


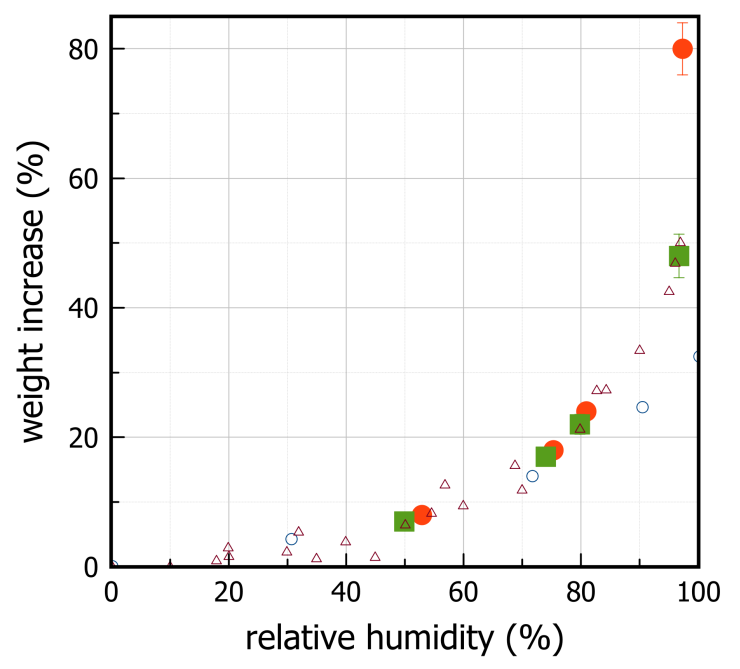

Figure 7. Sorption isotherms (water uptake as a function of the relative humidity) measured

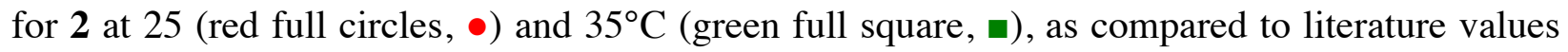
for polyacrylic acid at 25 (blue empty circles, $\circ$ ) and $30^{\circ} \mathrm{C}$ (purple empty triangles, $\triangle$ ). ${ }^{34-37}$

IR spectra for several samples containing increasing amounts of water (as measured by TGA) were collected, and showed a significant evolution in the $1600-1780 \mathrm{~cm}^{-1}$ range, as expected from previous studies on wet polymers containing carboxylic acid moieties (Figure S8 in the Supporting Information). ${ }^{38-39}$ The same evolution could also be observed in situ by registering IR spectra over time of a thin polyacid pellet fixed on top of an ATR probe, the whole setup having been placed in a constant humidity room at ambient temperature. The above spectral variations originates from a well-known phenomenon and are due to the very high sensitivity of the carbonyl vibration to its local environment, in particular with respect to molecular species capable of hydrogen-bonding to the $\mathrm{C}=\mathrm{O}$, such as water or other carboxylic acids. Unfortunately, no quantitative information could be obtained based on the spectral band analysis suggested by Ozaki et al. for polymethacrylic acid, which assigns specific vibrations in the $\mathrm{C}=\mathrm{O}$ stretching 
region to individual types of carboxyl group associations, i.e. cyclic dimers, free monomers, and oligomers. ${ }^{38}$ In particular, no spectrum simulations based on a simple curve-fitting procedure using the parameters provided by Ozaki et al. could be satisfactorily obtained. A secondderivative analysis of water-rich and water-poor samples suggests that the number of species needed to fully describe the entire set of spectra is much higher than for polymethacrylic acid (i.e., 4), possibly because of the coexistence of crystalline and amorphous phases.

\section{CONCLUSIONS}

A novel polyacid of simple yet highly symmetrical structure, $\left(\mathrm{CH}_{2}-\mathrm{CH}_{2}-\mathrm{C}(\mathrm{COOH})_{2}\right)_{\mathrm{n}}$, was designed and fully characterized. It can be obtained in two steps from easily synthesized and affordable di- $n$-propyl cyclopropane-1,1-dicarboxylate, with no structural defects detectable on the polymer structures as evidenced by high-resolution NMR. Its solubility in water and traditional organic solvents is quite low, except in formamide and $\mathrm{N}$-methylformamide. Despite the low attraction to water molecules in the liquid state, affinity in the solid-state with respect to gaseous water was found to be identical to those exhibited by polyacrylic acid.

The semi-crystalline nature of solid samples was evidenced by X-ray diffraction, solid-state NMR, and polarized light microscopy. It most probably arises from the high symmetry of the polyacid. NMR data indicate the presence of two spatial organizations of polymer chains in the amorphous phase, one consisting of cyclic dimers, the other of $\mathrm{H}$-bonded oligomers. $\left(\mathrm{CH}_{2}-\mathrm{CH}_{2}-\right.$ $\left.\mathrm{C}(\mathrm{COOH})_{2}\right)_{\mathrm{n}}$ samples are easy to handle but decomposes thermally above $100^{\circ} \mathrm{C}$, both in solution and in the solid state. Attempts at exploiting this feature are currently under study and will be reported shortly. 


\section{ASSOCIATED CONTENT}

\section{Supporting Information}

The following file is available free of charge on the ACS Publication website: PDF file containing the ${ }^{13} \mathrm{C}$ NMR and COSY spectra of PTD, a FT-IR monitoring of the precursor ester hydrolysis at alternate wavelengths, the raw autocorrelation data for the DLS experiments, polarized light microscopy images of several PTD solid samples and a FT-IR monitoring of PTD samples containing increasing amounts of water.

\section{AUTHOR INFORMATION}

\section{Corresponding Authors}

*Agustin Rios de Anda: Phone 33 (0)1 49781228 E-mail: rios@icmpe.cnrs.fr;

* Jacques Penelle: Phone 33 (0)1 49781275 E-mail: penelle@icmpe.cnrs.fr

\section{Author Contributions}

The manuscript was written through contributions of all authors. All authors have given approval to the final version of the manuscript.

\section{ACKNOWLEDGMENTS}

Partial funding of this work was provided by the French Agence Nationale de la Recherche (NORMATHER project, grant number ANR-14-CE16-0023). AB was the recipient of a PhD fellowship awarded by the French Ministry for Science \& Higher Education. Additional funding was provided by the East-Paris University (Créteil) and the CNRS, as well as by the French Ministry for Foreign Affairs for travel funding via the Kolmogorov program (Innovative 
Materials for Advanced Purification and Metal recovery Processes). The authors are very grateful to Nicolas Emery, Farah Daïli, Sophie Lout, Dimitri Ivanov and Sylvie Boileau for their technical assistance and/or discussions on some aspects of the reported work.

\section{REFERENCES}

1. Kauffman, G. B. Nylon at 50 - An Industrial Success ... and a Personal Tragedy. ChemTech 1988, $18,725-731$.

2. Kauffman, G. B. Wallace Hume Carothers and Nylon, the First Completely Synthetic Fiber. J. Chem. Educ. 1988, 65, 803-808.

3. Sivaram, S. Wallace Hume Carothers and the Birth of Rational Polymer Synthesis. Resonance 2017, 22, 339-353.

4. Smith, J. K.; Hounshell, D. A. Wallace H. Carothers and Fundamental Research at Du Pont. Science 1985, 229, 436-442.

5. Keiger, D. H., The Establishment of Modern Polymer Science by Wallace H. Carothers - An International Historic Chemical Landmark. American Chemical Society, Division of the History of Chemistry and The Office of Communications: 2000.

6. Allen, G. The Association of Carboxylic Acids. Q. Rev. Chem. Soc. 1953, 7, 255-278.

7. Bec, K. B.; Futami, Y.; Wojcik, M. J.; Nakajima, T.; Ozaki, Y. Spectroscopic and Computational Study of Acetic Acid and Its Cyclic Dimer in the Near-Infrared Region. J. Phys. Chem. A 2016, 120, 6170-6183. 
8. Lengvinaite, D.; Aidas, K.; Kimtys, L. Molecular Aggregation in Liquid Acetic Acid: Insight from Molecular Dynamics/Quantum Mechanics Modelling of Structural and NMR Properties. Phys. Chem. Chem. Phys. 2019, 21, 14811-14820.

9. Williams, D. H.; Gale, T. F.; Bardsley, B. The Increasing Tightness of Fully Associated States as a Function of Their Increasing Stability. The Dimerisation of Carboxylic Acids. $J$. Chem. Soc., Perkin Trans. 2 1999, 1331-1334.

10. Abraham, M. H. Scales of Solute Hydrogen-Bonding - Their Construction and Application to Physicochemical and Biochemical Processes. Chem. Soc. Rev. 1993, 22, 73-83.

11. Nuyken, O., Polymers of Acrylic Acid, Methacrylic Acid, Maleic Acid and Their Derivatives. In Handbook of Polymer Synthesis, 2nd ed.; Kricheldorf, H. R.; Nuyken, O.; G., S., Eds. Marcel Dekker: 2004; p 92.

12. Miller, M. L.; O'Donnell, K.; Skogman, J. Crystalline Polyacrylic Acid. J. Coll. Sci. 1962, $17,649-659$.

13. Benlahouès, A.; Brissault, B.; Boileau, S.; Penelle, J. Design of Optimized Reaction Conditions for the Efficient Living Anionic Polymerization of Cyclopropane-1,1-Dicarboxylates. Macromol. Chem. Phys. 2018, 219, 1700463/1-9.

14. Illy, N.; Boileau, S.; Buchmann, W.; Penelle, J.; Barbier, V. Control of End Groups in Anionic Polymerizations Using Phosphazene Bases and Protic Precursors as Initiating System (XH-But ${ }^{t}{ }_{4}$ Approach): Application to the Ring-Opening Polymerization of Cyclopropane-1,1Dicarboxylates. Macromolecules 2010, 43, 8782-8789. 
15. Illy, N.; Boileau, S.; Winnik, M. A.; Penelle, J.; Barbier, V. Thiol-Ene "Clickable" CarbonChain Polymers Based on Diallyl Cyclopropane-1,1-Dicarboxylate. Polymer 2012, 53, 903-912.

16. Illy, N.; Boileau, S.; Penelle, J.; Barbier, V. Metal-Free Activation in the Anionic RingOpening Polymerization of Cyclopropane Derivatives. Macromol. Rapid Commun. 2009, 30, $1731-1735$.

17. Penelle, J.; Xie, T. Ring-Opening Polymerization of Diisopropyl Cyclopropane-1,1Dicarboxylate under Living Anionic Conditions: A Kinetic and Mechanistic Study. Macromolecules 2000, 33, 4667-4672.

18. Elhawalamy, N.; Négrell, C.; Illy, N.; Brissault, B.; Penelle, J. Preliminary Investigations on a Simple Polyelectrolyte Derived from $\left(\mathrm{CH}_{2} \mathrm{CH}_{2} \mathrm{C}(\mathrm{COOH})_{2}\right)_{\mathrm{n}}$ : Unexpected SolubilityInsolubility Pattern Controlled Selectively by the Nature of the Alkali Counterion. Polymer, 2017, 116, 515-522.

19. Penelle, J.; Xie, T. Synthesis, Characterization, and Thermal Properties of Poly(trimethylene-1,1-dicarboxylate) Polyelectrolytes. Macromolecules 2001, 34, 5083-5089.

20. Kanade, P. B.; Pai, J. S. Moisture Sorption Method for Hygroscopic Samples Using a Modified Proximity Equilibration Cell. J. Food Sci. 1988, 53, 1218-1219.

21. Lang, K. W.; McCune, T. D.; Steinberg, M. P. A Proximity Equilibration Cell for RapidDetermination of Sorption Isotherms. J. Food Sci. 1981, 46, 936-938.

22. Greenspan, L. Humidity Fixed Points of Binary Saturated Aqueous Solutions. J. Res. Natl. Bur. Stand., Sect. A 1977, 81A, 89-96. 
23. Socrates, G., Infrared Characteristic Group Frequencies. 2nd ed.; John Wiley \& Sons: Chichester, 1994.

24. SDBS Database: https://sdbs.db.aist.go.jp (National Institute of Advanced Industrial Science and Technology), SDBS No. 19269HSP-46-596, accessed on August 28, 2019.

25. Sitar, S.; Aseyev, V.; Kogej, K. Differences in Association Behavior of Isotactic and Atactic Poly(methacrylic acid). Polymer 2014, 55, 848-854.

26. Atkins, E. D. T.; Nieduszynski, I. A.; Parker, K. D. Structural Components of Alginic Acid. 1. Crystalline-Structure of Poly-Beta-D-Mannuronic Acid - Results of X-Ray-Diffraction and Polarized Infrared Studies. Biopolymers 1973, 12, 1865-1878.

27. Draget, K. I.; SkjakBraek, G.; Christensen, B. E.; Gaserod, O.; Smidsrod, O. Swelling and Partial Solubilization of Alginic Acid Gel Beads in Acidic Buffer. Carbohydr. Polym. 1996, 29, 209-215.

28. Draget, K. I.; Stokke, B. T.; Yuguchi, Y.; Urakawa, H.; Kajiwara, K. Small-Angle X-Ray Scattering and Rheological Characterization of Alginate Gels. 3. Alginic Acid Gels. Biomacromolecules 2003, 4, 1661-1668.

29. Reichardt, C., Solvents and Solvent Effects in Organic Chemistry. 3rd ed.; Wiley-VCH: Weinheim, 2003.

30. Sikorski, P.; Atkins, E. D. T.; Kagumba, L. C.; Penelle, J. Structure and Morphology of Poly(diethyl trimethylene-1,1-dicarboxylate) Crystals. Macromolecules 2002, 35, 6975-6984. 
31. Fortier-McGill, B.; Toader, V.; Reven, L. ${ }^{1} \mathrm{H}$ Solid State NMR Study of Poly(methacrylic acid) Hydrogen-Bonded Complexes. Macromolecules 2012, 45, 6015-6026.

32. Asano, A.; Eguchi, M.; Kurotu, T. Solid-State C-13 NMR Study on Thermal Dehydration Process of Poly(methacrylic acid)(PMAA). J. Polym. Sci., Part B: Polym. Phys. 1999, 37, $2007-$ 2012.

33. Haas, D.J.; Brenner, S.A. Application of the Symbolic Addition Method to Dimethylmalonic Acid. Acta Cryst. 1966, 20, 709-711.

34. Thijs, H. M. L.; Becer, C. R.; Guerrero-Sanchez, C.; Fournier, D.; Hoogenboom, R.; Schubert, U. S. Water Uptake of Hydrophilic Polymers Determined by a Thermal Gravimetric Analyzer with a Controlled Humidity Chamber. J. Mater. Chem. 2007, 17, 4864-4871.

35. Hughes, L. J. T.; Fordyce, D. B. Sorption of Water Vapor by Water-Soluble Polymers: Kinetic, Equilibrium, and Glass Temperature Data. J. Polym. Sci. 1956, 22, 509-526.

36. Chang, M. J.; Myerson, A. S.; Kwei, T. K. The Effect of Hydrogen Bonding on Vapor Diffusion in Water-Soluble Polymers. J. Appl. Polym. Sci. 1997, 66, 279-291.

37. Borisevich, A. A.; Chalyh, A. E.; Kulagina, G. S.; Gerasimov, V. K. Sorption of Water by Polyacrylic Acid. Prot.Met. Phys. Chem. Surf. 2009, 45, 675-678.

38. Dong, J.; Ozaki, Y.; Nakashima, K. Infrared, Raman, and Near-Infrared Spectroscopic Evidence for the Coexistence of Various Hydrogen-Bond Forms in Poly(acrylic acid). Macromolecules 1997, 30, 1111-1117. 
39. Tajiri, T.; Morita, S.; Ozaki, Y. Hydration Mechanism on a Poly(Methacrylic Acid) Film Studied by in Situ Attenuated Total Reflection Infrared Spectroscopy. Polymer 2009, 50, 57655770. 